\title{
AURKB: a promising biomarker in clear cell renal cell carcinoma
}

\author{
Bangbei Wan Equal first author, 1 , Yuan Huang ${ }^{\text {Equal first author, } 2}{ }^{\text {, Bo Liu }}{ }^{3}$, Likui Lu ${ }^{4}$, Cai Lv ${ }^{\text {Corresp. } 1}$ \\ ${ }^{1}$ Urology, Haikou Municipal People's Hospital and Central South University Xiangya Medical College Affiliated Hospital, Haikou, China \\ Neurology, Haikou Municipal People's Hospital and Central South University Xiangya Medical College Affiliated Hospital, Haikou, China \\ 3 \\ 4 Institute for Fetology, First Affiliated Hospital of Soochow University, Suzhou, China \\ Corresponding Author: Cai Lv \\ Email address: Ivcai815@163.com
}

Background: Aurora kinase $\mathrm{B}(A U R K B)$ is an important carcinogenic factor in various tumors, while its role in clear cell renal cell carcinoma (ccRCC) still remains unclear. This study aimed to investigate its prognostic value and mechanism of action in ccRCC.

Methods: Gene expression profiles and clinical data of ccRCC patients were downloaded from The Cancer Genome Atlas database. R software was utilized to analyze the expression and prognostic role of $A U R K B$ in CCRCC. Gene set enrichment analysis (GSEA) was used to analyze AURKB related signaling pathways in CCRCC.

Results: $A U R K B$ was expressed at higher levels in $C C R C C$ tissues than normal kidney tissues. Increased $A U R K B$ expression in $C C R C C$ correlated with high histological grade, pathological stage, $\mathrm{T}$ stage, $\mathrm{N}$ stage and distant metastasis (M stage). Kaplan-Meier survival analysis suggested that high AURKB expression patients had a worse prognosis than patients with low $A U R K B$ expression levels. Multivariate Cox analysis showed that $A U R K B$ expression is a prognostic factor of CCRCC. GSEA indicated that genes involved in autoimmune thyroid disease, intestinal immune network for $\lg A$ production, antigen processing and presentation, cytokine-cytokine receptor interaction, asthma, etc., were differentially enriched in the $A U R K B$ high expression phenotype.

Conclusions: $A U R K B$ is a promising biomarker for predicting prognosis of $C C R C C$ patients and a potential therapeutic target. In addition, $A U R K B$ might regulate progression of CCRCC through modulating intestinal immune network for IgA production and cytokine-cytokine receptor interaction, etc. signaling pathways. However, more research is necessary to validate the findings. 


\title{
$A U R K B$ : a promising biomarker in clear cell renal cell carcinoma
}

\author{
Bangbei Wan ${ }^{1 \&}$, Yuan Huang ${ }^{2 \&}, \mathrm{Bo} \mathrm{Liu}^{3}$, Likui Lu${ }^{4}$, Cai Lv ${ }^{1}$
}

Affiliations: ${ }^{1}$ Urology, Haikou Municipal People's Hospital and Central South University Xiangya Medical College Affiliated Hospital, Haikou, China; ${ }^{2}$ Neurology, Haikou Municipal People's Hospital and Central South University Xiangya Medical College Affiliated Hospital, Haikou, China; ${ }^{3}$ Laboratory of Developmental Cell Biology and Disease, School of Ophthalmology and Optometry and Eye Hospital, Wenzhou, China. ${ }^{4}$ Institute for Fetology, First Affiliated Hospital of Soochow University, Suzhou, China.

$\&$ These authors contributed equally to this work and should be regarded as co-first authors.

Correspondence: Corresponding author: Cai Lv, Department of Urology, Haikou Municipal People's Hospital and Central South University Xiangya Medical College Affiliated Hospital, Haikou, China. E-mail: 1vcai815@163.com

\section{Abstract}

Background: Aurora kinase $\mathrm{B}(A U R K B)$ is an important carcinogenic factor in various tumors, while its role in clear cell renal cell carcinoma (ccRCC) still remains unclear. This study aimed to investigate its prognostic value and mechanism of action in ccRCC.

Methods: Gene expression profiles and clinical data of ccRCC patients were downloaded from The Cancer Genome Atlas database. $\mathrm{R}$ software was utilized to analyze the expression and prognostic role of $A U R K B$ in ccRCC. Gene set enrichment analysis (GSEA) was used to analyze $A U R K B$ related signaling pathways in ccRCC.

Results: $A U R K B$ was expressed at higher levels in ccRCC tissues than normal kidney tissues. Increased $A U R K B$ expression in ccRCC correlated with high histological grade, pathological stage, $\mathrm{T}$ stage, $\mathrm{N}$ stage and distant metastasis (M stage). Kaplan-Meier survival analysis suggested that high $A U R K B$ expression patients had a worse prognosis than patients with low $A U R K B$ expression levels. Multivariate Cox analysis showed that AURKB expression is a prognostic factor of ccRCC. GSEA indicated that genes involved in autoimmune thyroid disease, intestinal immune network for IgA production, antigen processing and presentation, cytokinecytokine receptor interaction, asthma, etc., were differentially enriched in the AURKB high expression phenotype.

Conclusions: $A U R K B$ is a promising biomarker for predicting prognosis of ccRCC patients and a potential therapeutic target. In addition, $A U R K B$ might regulate progression of ccRCC through modulating intestinal immune network for IgA production and cytokine-cytokine receptor interaction, etc. signaling pathways. However, more research is necessary to validate the findings.

Keywords: $A U R K B$; ccRCC; TCGA database; prognosis; GESA 


\section{Introduction}

Renal cell carcinoma (RCC) is one of the most common malignant tumors of the urinary system, and clear cell renal cell carcinoma (ccRCC) is the most common pathological subtype (Srigley et al., 2013). Morbidity and mortality of ccRCC are increasing year by year, while the mechanism of ccRCC development still remain unclear (Dutcher., 2013). Hence, biomarkers that can be used to diagnose, treat and predict prognosis of ccRCC, are urgently needed.

Aurora kinase B (AURKB), located on human chromosome 17p13.1, encodes a member of the aurora kinase subfamily of serine/threonine kinases. Previous researches have reported that aberrant $A U R K B$ expression is related to tumorigenesis and progression of tumors (Zhu et al., 2019). Single nucleotide polymorphisms (SNPs) of $A U R K B$ were associated with occurrence of gastric cancer (GC). rs2289590 in AURKB might contribute to susceptibility for the development of gastric cancer (Mesic et al., 2017). In thyroid cancer, Sorrentino et al. (2005) found that $A U R K B$ was not detected in normal thyroid tissue, but it was overexpressed in thyroid carcinoma. Further experiments indicated that silencing $A U R K B$ can obviously inhibit the growth of thyroid carcinoma cells. Hence, they thought that $A U R K B$ was an important protein in the progression of thyroid carcinomas and a promising candidate for targeted treatment. Besides, $A U R K B$ also plays an important role in non-neoplastic disease. In asthenozoospermia, over-expression of $A U R K B$ might be associated with development of asthenozoospermia. Over-expression of $A U R K B$ can decrease glycolytic activities, conferring to the occurrence and progression of asthenozoospermia (Zhou et al., 2018). Generally, the several researches have suggested the important role of AURKB in tumors and non-neoplastic disease. However, few studies about the relationship between AURKB and ccRCC have been reported so far and the role of AURKB in ccRCC remains elusive.

In this work, we attempted to reveal the significance of $A U R K B$ expression in ccRCC and the mechanisms related to ccRCC progression. We compared $A U R K B$ mRNA expression between tumor tissues and normal tissues. We then analyzed the relationship between $A U R K B$ mRNA expression and clinical parameters of ccRCC and correlated them with patients' overall survival (OS) and disease-free survival (DFS). Results indicated that patients with high $A U R K B$ expression have poorer prognosis than patients with low $A U R K B$ expression. In addition, to further understand the $A U R K B$-related biological pathways involved in ccRCC, Gene set enrichment analysis (GSEA) was performed. Results showed that twenty-one genes were evidently enriched in patients with high $A U R K B$ expression, including intestinal immune network for IgA production, cytokine-cytokine receptor interaction, natural killer cell mediated cytotoxicity, cell cycle and cell adhesion molecules (CAMs), etc.

\section{Materials and methods}

\section{Database}

Gene expression profiles of ccRCC patients and clinical data of patients such as age, gender, pathological stage, histological grade, survival, and outcome were downloaded from TCGA 
82 database (https://portal.gdc.cancer.gov/). In addition, Drug sensitivity data of ccRCC cell lines 83 were obtained from genomics of drug sensitivity in cancer (GDSC) database 84 (https://portals.broadinstitute.org/ccle/about). We then utilized R software (https://www.r85 project.org/) to process all data.

86 Firstly, we extracted clinical data of ccRCC patients and data of gene expression profiles. We then obtained clinical data of 530 patients who possessed complete OS information and a gene expression matrix document. Secondly, we obtained expression of $A U R K B$ data from the gene expression matrix document and analyzed the relationship between expression of $A U R K B$ and clinical parameters including age, gender, histological grade, pathological stage, T stage, N stage, and $\mathrm{M}$ stage. Thirdly, the ccRCC patients be divided into two groups based on median value of $A U R K B$ expression (high $A U R K B$ expression group and low $A U R K B$ expression group) and analyzed their overall survival (OS) and disease-free survival (DFS). Fourthly, we utilized some clinical parameters, that correlated with prognosis of ccRCC, and $A U R K B$ to construct a prognostic model. Finally, we analyzed that the difference between sensitivity of AURKB targeted drug and other targeted drugs for ccRCC.

\section{Gene set enrichment analysis}

Gene expression profiles of ccRCC patients were divided into two groups (high expression group and low expression group) according to the median value of expression of $A U R K B$. GSEA was utilized to detect potential mechanisms underlying the effect of $A U R K B$ expression on ccRCC prognosis. Gene set permutations were performed 1000 times for each analysis. Gene sets with a $p$-value $<0.05$ and false discovery rate $($ FDR $)<0.05$ were regarded as significantly enriched.

\section{Statistical analysis}

All statistical analyses were performed through $\mathrm{R}$ software and $p<0.05$ was regarded as statistically significant. The relationship between expression levels of $A U R K B$ and clinical parameters was analyzed via the Wilcoxon signed-rank test, Kruskal-Wallis test and logistic regression. The correlation between expression levels of $A U R K B$, and patients' OS and DFS were analyzed using the Kaplan-Meier method. Univariate Cox analysis was used to select possible prognostic factors, and multivariate Cox analysis was utilized to verify the correlations between $A U R K B$ mRNA expression and survival along with other clinical features. A receiver operating characteristic (ROC) curve was used to evaluate the accuracy of models that predicted prognosis using the survival ROC package. An area under the curve (AUC) value of 0.75 or bigger was deemed an excellent predictive value, and values of 0.6 or larger were regarded as acceptable for survival predictions. The chi-square test be used to compare difference between sensitivity of target drugs in ccRCC cell lines.

\section{Results}

\section{Clinical parameters of patients}

The clinical data of 530 ccRCC patients were obtained from the TCGA database, and included 
122

123

age, gender, histological grade, pathological stage, survival, and outcome, etc. (Table 1).

\section{High $A U R K B$ expression in ccRCC}

Expression levels of $A U R K B$ in $539 \mathrm{ccRCC}$ and 72 normal kidney tissues were compared via Wilcoxon signed-rank test, and the results showed that $A U R K B$ was highly expressed in ccRCC compared to normal kidney tissues $(p<0.05)$ (Fig. 1A). We further analyzed the expression of $A U R K B$ in 72 pairs of ccRCC tissues and matched non-cancerous adjacent tissues using Wilcoxon singed-rank test, and found that $A U R K B$ was significantly overexpressed in ccRCC tissues $(p<0.05)$ (Fig. 1B). These results suggested that $A U R K B$ may be a carcinogenic gene in ccRCC.

\section{Correlations between $A U R K B$ expression and clinical parameters in ccRCC patients}

The relationship between $A U R K B$ expression and patients' clinical parameters was analyzed by $\mathrm{R}$ software. Results indicated that with the increase of AURKB expression, these clinical parameters (histological grade, pathological stage, T stage, $\mathrm{N}$ stage and $\mathrm{M}$ stage) also elevated (all $p<0.05)$. Furthermore, expression of AURKB in male was higher than female $(p<0.05)$ (Fig. 2).

Logistic regression analysis shown that increased $A U R K B$ expression in ccRCC was obviously correlated with gender $(\mathrm{OR}=1.49$ for Female vs. Male, $p=0.029)$, histological grade $(\mathrm{OR}=$ 2.44 for $\mathrm{G} 1 / \mathrm{G} 2$ vs. G3/G4, $p=6.97 \mathrm{E}-07$ ), pathological stage ( $\mathrm{OR}=1.17$ for stage I vs. stage III, $p=0.000 ; \mathrm{OR}=3.62$ for stage I vs. stage IV, $p=2.42683 \mathrm{E}-06)$, TNM stage (OR $=2.84$ for $\mathrm{T} 1 / \mathrm{T} 2$ vs. T3/T4, $p=3.12 \mathrm{E}-08$; OR $=4.75$ for N0 vs. N1, $p=0.017$; OR $=2.99$, for M0 vs. M1, $p=4.8776 \mathrm{E}-05$ ) (Table 2). These results indicated that ccRCC with increased $A U R K B$ expression is prone to progress to a more advanced stage, lymph node metastasis distant metastasis.

\section{Prognostic role of $A U R K B$ expression in ccRCC Patients}

To further understand the prognostic role of $A U R K B$ expression in ccRCC, all ccRCC patients were categorized according to the median $A U R K B$ expression value (high $A U R K B$ expression group and low $A U R K B$ expression group). Patients who lacked complete clinical data were excluded from the analysis. Kaplan-Meier survival analysis indicated that the high $A U R K B$ expression group had worse prognosis compared with the low $A U R K B$ expression group $(p<$ 0.05) (Fig. 3). The univariate analysis indicated that high $A U R K B$ expression was associated with poorer OS and DFS $(p<0.05)$. Other clinical parameters, such as pathological stage and histological grade, also correlated with worse OS and DFS $(p<0.05)$ (Table 3$)$.

To confirm the prognostic value of $A U R K B$ expression, multivariate analysis was performed. The results showed that age, histological grade, pathological stage and $A U R K B$ expression were independently associated with OS $(p<0.05)$, and histological grade, pathological stage and $A U R K B$ were independently correlated with DFS $(p<0.05)$. Overall, these results suggest that $A U R K B$ is an independent prognostic factor of ccRCC (Fig. 4 and Table 3 ). 


\section{Prognostic models of $A U R K B$ expression and new nomograms}

As the expression of $A U R K B$ plays an important role in OS and DFS in ccRCC, we attempted to explore whether it can be used to create better prognostic models. Two new nomograms were constructed to predict OS and DFS, 3 and 5 years after surgery (Fig. 5A and 5C). A ROC curve was used to estimate the accuracy of the two models, and the results indicated that the two models were able to accurately predict OS and DFS at 3 and 5 years after surgery (the areas under the ROC curve were 0.792 (3-year OS), 0.748 (5-year OS), 0.851 (3-year DFS) and 0.837 (5-year DFS)) (Fig. 5B and 5D).

\section{Sensitivity analysis of AURKB targeted drug}

Cabozantinib (targets: VEGFR, MET, RET, KIT, FLT1, FLT3, FLT4, TIE2, AXL) and Axitinib (targets: PDGFR, KIT, VEGFR) are common target drug for ccRCC. Genentech Cpd 10 (targets: $A U R K A, A U R K B)$ also is a target drug. To further validate $A U R K B$ might become a potential treatment target in ccRCC, drug sensitivity analysis of ccRCC cell lines was performed. Results showed that 2 ccRCC cell lines $(n=31)$ were sensitive to Cabozantinib, 21 ccRCC cell lines $(n=$ 31) were sensitive to Genentech Cpd 10, and none ccRCC cell lines $(n=24)$ are sensitive to Axitinib (Table 4 and Fig. 6). These results suggested that ccRCC cell lines were more sensitive to Genentech Cpd 10 than Cabozantinib and Axitinib $(p<0.05)$, and AURKB probably become a promising target to treat ccRCC.

\section{Identification of $A U R K B$ related signaling pathways}

GSEA was used to screen signaling pathways involved in ccRCC between low and high $A U R K B$ expression data set. GSEA indicated significant differences (FDR $<0.05$, NOM $p$-value $<0.05$ ) in enrichment of MSigDB Collection (c2.cp.v6.2.symbols.gmt).

Twenty-one signaling pathways involved in autoimmune thyroid disease, intestinal immune network for IgA production, antigen processing and presentation, cytokine-cytokine receptor interaction, asthma, type I diabetes mellitus, primary immunodeficiency, graft versus host disease, allograft rejection, base excision repair, homologous recombination, natural killer cell mediated cytotoxicity, cytosolic DNA sensing pathway, viral myocarditis, hematopoietic cell lineage, DNA replication, systemic lupus erythematosus, leishmania infection, cell cycle, cell adhesion molecules (CAMs) and proteasome were differentially enriched in the AURKB high expression phenotype (Table 5). Five signaling pathways that may be closely connected to the progression of ccRCC tumors are shown in Fig. 7.

\section{Discussion}

Many studies have suggested that $A U R K B$ plays a vital role in tumorigenesis and tumor progression (Zhu et al., 2019; Mesic et al., 2017; Kotian et al., 2017). AURKB has been shown to be involved in the development of breast cancer, and its expression has been associated with breast cancer prognosis (Liao et al., 2018; Naorem, Muthaiyan \& Venkatesan, 2019). In nonsmall cell lung cancer (NSCLC), $A U R K B$ has been shown to be overexpressed and correlated with poorer prognosis of patients. Its overexpression was shown to significantly promote 
204 proliferation of NSCLC cells via inhibiting the p53-related pathway. In addition, expression of $205 A U R K B$ has also been associated with drug resistance in NSCLC. Overexpression of $A U R K B$ 206 increased drug resistance in NSCLC cells, whereas $A U R K B$ knockdown re-sensitized NSCLC 207 cells to chemotherapeutic drugs (Yu et al., 2018). In colorectal cancer (CRC), AURKB has also 208 been shown to act as an important oncogenic factor, be involved in the development of CRC, and

209 promoted drug resistance and progression of CRC though regulation of the Wnt signaling pathway and the p53-related pathway (Subramaniyan, Kumar \& Mathan, 2017; Nair et al., 2009; Wu et al., 2011; Pohl et al., 2011). All these studies have suggested that AURKB promotes carcinogenesis and is associated with drug resistance.

In this work, we sought to identify the role of $A U R K B$ expression in ccRCC progression, particularly, its role as a prognostic factor in ccRCC. Moreover, we also attempted to screen $A U R K B$-related signaling pathways in ccRCC to contribute to the understanding the potential mechanism involved in the regulation of ccRCC development by $A U R K B$.

Firstly, we compared that expression of $A U R K B$ in ccRCC and normal tissues. The results showed that $A U R K B$ was overexpressed in ccRCC tissues compared to normal tissues, and its expression was associated with pathological stage, histological grade, $\mathrm{T}$ stage, $\mathrm{M}$ stage, and $\mathrm{N}$ stage.

Secondly, Kaplan-Meier survival analysis showed that compared to the low $A U R K B$ expression group, the high $A U R K B$ expression group of patients had poorer OS and DFS. Moreover, some variables were also associated with the prognosis of ccRCC patients, including pathological stage, histological grade, $\mathrm{T}$ stage, and $\mathrm{M}$ stage. In addition, multivariate analysis confirmed that $A U R K B$ expression was a prognostic factor. Another, the drug sensitivity analysis of ccRCC cell lines suggested that various cell lines were sensitive to Genentech Cpd 10, and AURKB might be a promising target to treat ccRCC.

Finally, we constructed prognostic models of $A U R K B$ expression, and the area under the curve (AUC) values proved that the new prognostic models can accurately predict OS and PFS. Furthermore, $A U R K B$ related signaling pathways in ccRCC were analyzed by GSEA, and results suggested that intestinal immune network for IgA production, cytokine-cytokine receptor interaction, natural killer cell mediated cytotoxicity, cell cycle and cell adhesion molecules (CAMs), correlate with progression of ccRCC. It has been shown that intestinal immune network for IgA production play a pivotal role in tumor progression (Liang et al., 2018). Yang et al. (2018) have found that activation of intestinal immune network for IgA production signaling pathway promoted malignant behavior of tumor cells. Additionally, cytokine-cytokine receptor interaction was a significant immune signaling pathway, as it can modulate interaction of cytokines, thereby regulating occurrence and progression of cancers (Tumino et al., 2019; Nagarsheth, Wicha \& Zou, 2017). Natural killer cell mediated cytotoxicity plays a vital role in modulating tumor microenvironment; their activation was closely related to the progression of tumors and prognosis of cancer patients (Malmberg et al., 2017; Chan et al., 2019; Bassani et al., 2019). The cell cycle controls the progression of tumors (Roy et al., 2017), and its activation can significantly promote proliferation of tumor cells, thus accelerating tumor growth (Eifler \& Vertegaal, 2015; Mast et al., 2019). Increasing amount of evidence has indicated that alterations 
245

246

247

248

249

250

251

252

253

254

255

256

257

258

259

260

261

262

263

264

265

266

267

268

269

270

271

272

273

274

275

276

277

278

279

280

281

282

283

284

285

in the adhesion properties of neoplastic cells play an important role in the development and progression of tumors, and cell adhesion molecules (CAMs) are involved in the adhesion of neoplastic cells, and participate in metastasis, migration and invasion of tumors (Méndez \& Bosch, 2011; Xin, Dong \& Guo, 2015; Okegawa et al., 2004). All these results suggest that $A U R K B$ promotes oncogenesis and progression of ccRCC through regulating multiple signaling pathways.

At present, many studies have already indicated that $A U R K B$ is a promising therapeutic target in various cancers, such as non-small cell lung cancer (NSCLC) (Bertran-Alamillo et al., 2019), gastric cancer (GC) (He et al., 2019), leukemia (He et al., 2016), prostate cancer (PC) (Addepalli et al., 2010), and breast cancer (Han et al., 2017). Additionally, in the present study, we found that $A U R K B$ is a promising biomarker in the treatment of ccRCC and a predictor of prognosis.

Inevitably, our study also has several limitations. Firstly, the data we analyzed in the present study were extracted from several public databases, which had not been verified. Secondly, the mechanisms by which AURKB regulates the occurrence and progression of ccRCC need further exploration. Finally, our study found that ccRCC cell lines were more sensitive to AURKBtargeting drug (Genentech Cpd 10) than the conventional targeted drugs (Cabozantinib and Axitinib). However, more studies are necessary to identify whether AURKB could be used as a target for ccRCC treatment.

\section{Conclusions}

In summary, our study suggests that $A U R K B$ is over-expressed in ccRCC, and it is a valuable prognostic factor for predicting OS and DFS of ccRCC patients. $A U R K B$ can promote development of ccRCC via various signaling pathways including intestinal immune network for IgA production, cytokine-cytokine receptor interaction, natural killer cell mediated cytotoxicity, cell cycle and cell adhesion molecules (CAMs). In addition, $A U R K B$ might be a promising therapeutic target for ccRCC. However, more research is required to verify the findings of this study.

\section{References:}

Srigley JR, Delahunt B, Eble JN, Egevad L, Epstein JI, Grignon D, Hes O, Moch H, Montironi R, Tickoo SK, Zhou M, Argani P. 2013. The International Society of Urological Pathology (ISUP) Vancouver Classification of Renal Neoplasia. Am J Surg Pathol 37(10):1469-89 DOI 10.1097/PAS.0b013e318299f2d1.

Dutcher JP. 2013. Recent developments in the treatment of renal cell carcinoma. Ther Adv Urol 5(6):338-53 DOI 10.1177/1756287213505672.

Zhu Q, Ding L, Zi Z, Gao S, Wang C, Wang Y, Zhu C, Yuan Z, Wei F, Cai Q. 2019. Viral-Mediated AURKB Cleavage Promotes Cell Segregation and Tumorigenesis. Cell Rep 27(5):1633-1636 DOI 
Mesic A, Markocic E, Rogar M, Juvan R, Hudler P, Komel R. 2017. Single nucleotide polymorphisms rs911160 in AURKA and rs2289590 in AURKB mitotic checkpoint genes contribute to gastric cancer susceptibility. Environ Mol Mutagen 58(9):701-711 DOI 10.1002/em.22129.

Sorrentino R, Libertini S, Pallante PL, Troncone G, Palombini L, Bavetsias V, Spalletti-Cernia D, Laccetti P, Linardopoulos S, Chieffi P, Fusco A, Portella G. 2005. Aurora B overexpression associates with the thyroid carcinoma undifferentiated phenotype and is required for thyroid carcinoma cell proliferation. J Clin Endocrinol Metab 90(2):928-35 DOI 10.1210/jc.20041518.

Zhou R, Zhang Y, Du G, Han L, Zheng S, Liang J, Huang X, Qin Y, Wu W, Chen M, Wu D, Song L, Fu G, Lv S, Xia Y, Lu C, Wang X. 2018. Down-regulated let-7b-5p represses glycolysis metabolism by targeting AURKB in asthenozoospermia. Gene 663:83-87 DOI 10.1016/j.gene.2018.04.022.

Kotian S, Zhang L, Boufraqech M, Gaskins K, Gara SK, Quezado M, Nilubol N, Kebebew E. 2017. Dual Inhibition of HDAC and Tyrosine Kinase Signaling Pathways with CUDC-907 Inhibits Thyroid Cancer Growth and Metastases. Clin Cancer Res 23(17):5044-5054 DOI 10.1158/1078-0432.CCR-17-1043.

Liao Y, Liao Y, Li J, Li J, Fan Y, Xu B. 2018. Polymorphisms in AURKA and AURKB are associated with the survival of triple-negative breast cancer patients treated with taxane-based adjuvant chemotherapy. Cancer Manag Res 10:3801-3808 DOI 10.2147/CMAR.S174735.

Naorem LD, Muthaiyan M, Venkatesan A. 2019. Integrated network analysis and machine learning approach for the identification of key genes of triplenegative breast cancer. J Cell Biochem 120(4):6154-6167 DOI 10.1002/jcb.27903.

Yu J, Zhou J, Xu F, Bai W, Zhang W. 2018. High expression of Aurora-B is correlated with poor prognosis and drug resistance in non-small cell lung cancer. Int J Biol Markers 33(2):215-221 DOI 10.1177/1724600817753098.

Subramaniyan B, Kumar V, Mathan G. 2017. Effect of sodium salt of Butrin, a novel compound isolated from Butea monosperma flowers on suppressing the expression of SIRT1 and Aurora B kinase-mediated apoptosis in colorectal cancer cells. Biomed Pharmacother 90:402-413 DOI 10.1016/j.biopha.2017.03.086.

Nair JS, Ho AL, Tse AN, Coward J, Cheema H, Ambrosini G, Keen N, Schwartz GK. 2009. Aurora B kinase regulates the postmitotic endoreduplication checkpoint via phosphorylation of the retinoblastoma protein at serine 780 . Mol Biol Cell 20(8):2218-28 DOI 10.1091/mbc.E08-08-0885.

Wu L, Ma CA, Zhao Y, Jain A. 2011. Aurora B interacts with NIR-p53, leading to 553 phosphorylation in its DNA-binding domain and subsequent functional suppression. J Biol Chem 286(3):2236-44 DOI 
10.1074/jbc.M110.174755.

Pohl A, Azuma M, Zhang W, Yang D, Ning Y, Winder T, Danenberg K, Lenz HJ. 2011. Pharmacogenetic profiling of Aurora kinase $B$ is associated with overall survival in metastatic colorectal cancer. Pharmacogenomics $\mathrm{J}$ 11(2):93-9 DOI 10.1038/tpj.2010.18.

Liang L, Zeng JH, Qin XG, Chen JQ, Luo DZ, Chen G. 2018. Distinguishable Prognostic Signatures of Left- and Right-Sided Colon Cancer: a Study Based on Sequencing Data. Cell Physiol Biochem 48(2):475-490 DOI $10.1159 / 000491778$.

Yang Z, Tao Y, Xu X, Cai F, Yu Y, Ma L. 2018. Bufalin inhibits cell proliferation and migration of hepatocellular carcinoma cells via APOBEC 3F induced intestinal immune network for IgA production signaling pathway. Biochem Biophys Res Commun 503(3):2124-2131 DOI 10.1016/j.bbrc.2018.07.169.

Tumino N, Martini S, Munari E, Scordamaglia F, Besi F, Mariotti FR, Bogina G, Mingari MC2, Vacca P, Moretta L. 2019. Presence of innate lymphoid cells in pleural effusions of primary and metastatic tumors: Functional analysis and expression of PD-1 receptor. Int J Cancer (in press) DOI $10.1002 / \mathrm{ijc} .32262$.

Nagarsheth N, Wicha MS, Zou W. 2017. Chemokines in the cancer microenvironment and their relevance in cancer immunotherapy. Nat Rev Immunol 17(9):559-572 DOI 10.1038/nri.2017.49.

Malmberg KJ, Carlsten M, Björklund A, Sohlberg E, Bryceson YT, Ljunggren HG. 2017. Natural killer cell-mediated immunosurveillance of human cancer. Semin Immunol 31:20-29 DOI 10.1016/j.smim.2017.08.002.

Chan LL, Wucherpfennig KW, de Andrade LF. 2019. Visualization and quantification of NK cell-mediated cytotoxicity over extended time periods by image cytometry. J Immunol Methods 469:47-51 DOI 10.1016/j.jim.2019.04.001.

Bassani B, Baci D, Gallazzi M, Poggi A, Bruno A, Mortara L. 2019. Natural Killer Cells as Key Players of Tumor Progression and Angiogenesis: Old and Novel Tools to Divert Their Pro-Tumor Activities into Potent Anti-Tumor Effects. Cancers (Basel) 11(4) DOI 10.3390/cancers11040461.

Roy D, Sheng GY, Herve S, Carvalho E, Mahanty A, Yuan S, Sun L. 2017. Interplay between cancer cell cycle and metabolism: Challenges, targets and therapeutic opportunities. Biomed Pharmacother 89:288-296 DOI 10.1016/j.biopha.2017.01.019.

Eifler K, Vertegaal ACO. 2015. SUMOylation-Mediated Regulation of Cell Cycle Progression and Cancer. Trends Biochem Sci 40(12):779-793 DOI 10.1016/j.tibs.2015.09.006.

Mast JM, Tse D, Shee K, Lakshmi Kuppusamy M, Kmiec MM, Kálai T, 
368

369

370

371

372

373

374

375

376

377

378

379

380

381

382

383

384

385

386

387

388

389

390

391

392

393

394

395

396

397

398

399

400

401

402

403
Kuppusamy P. 2019. Diarylidenylpiperidones, H-4073 and HO-3867, Induce G2/M Cell-Cycle Arrest, Apoptosis and Inhibit STAT3 Phosphorylation in Human Pancreatic Cancer Cells. Cell Biochem Biophys 77(2):109-119 DOI 10.1007/s12013-019-00873-6.

de Méndez MT, Bosch AL. 2011. Abnormal immunoexpression of cell adhesion molecules (CAMs) in cervical cancer. Int J Surg Pathol 19(6):733-42 DOI $10.1177 / 1066896909343435$.

Xin M, Dong XW, Guo XL. 2015. Role of the interaction between galectin-3 and cell adhesion molecules in cancer metastasis. Biomed Pharmacother 69:17985 DOI 10.1016/j.biopha.2014.11.024.

Okegawa T, Pong RC, Li Y, Hsieh JT. 2004. The role of cell adhesion molecule in cancer progression and its application in cancer therapy. Acta Biochim Pol 51(2):445-57 DOI 035001445

Bertran-Alamillo J, Cattan V, Schoumacher M, Codony-Servat J, GiménezCapitán A, Cantero F, Burbridge M, Rodríguez S, Teixidó C, Roman R, Castellví J, García-Román S, Codony-Servat C, Viteri S, Cardona AF, Karachaliou N, Rosell R, Molina-Vila MA. 2019. AURKB as a target in non-small cell lung cancer with acquired resistance to anti-EGFR therapy. Nat Commun 10(1):1812 DOI 10.1038/s41467-019-09734-5.

He J, Qi Z, Zhang X, Yang Y, Liu F, Zhao G, Wang Z. 2019. Aurora kinase B inhibitor barasertib (AZD1152) inhibits glucose metabolism in gastric cancer cells. Anticancer Drugs 30(1):19-26 DOI 10.1097/CAD.0000000000000684. He SJ, Shu LP, Zhou ZW, Yang T, Duan W, Zhang X, He ZX, Zhou SF. 2016. Inhibition of Aurora kinases induces apoptosis and autophagy via AURKB/p70S6K/RPL15 axis in human leukemia cells. Cancer Lett 382(2):215-230 DOI 10.1016/j.canlet.2016.08.016.

Addepalli MK, Ray KB, Kumar B, Ramnath RL, Chile S, Rao H. 2010. RNAimediated knockdown of AURKB and EGFR shows enhanced therapeutic efficacy in prostate tumor regression. Gene Ther 17(3):352-9 DOI 10.1038/gt.2009.155.

Han EH, Min JY, Yoo SA, Park SJ, Choe YJ, Yun HS, Lee ZW, Jin SW, Kim HG, Jeong HG, Kim HK, Kim ND, Chung YH. 2017. A small-molecule inhibitor targeting the AURKC-I $\mathrm{BB} \alpha$ interaction decreases transformed growth of MDA-MB-231 breast cancer cells. Oncotarget 8(41):69691-69708 DOI 10.18632/oncotarget.18883. 
Figure 1

$A U R K B$ was significantly overexpressed in CCRCC compared to normal or adjacent normal tissues.

(A) AURKB was significantly upregulated in cancer tissues compared to normal tissues ( $p<$ 0.05). (B) AURKB was expressed at higher levels in $c c R C C(p<0.05)$ compared to 72 pairs of non-cancerous adjacent tissues.
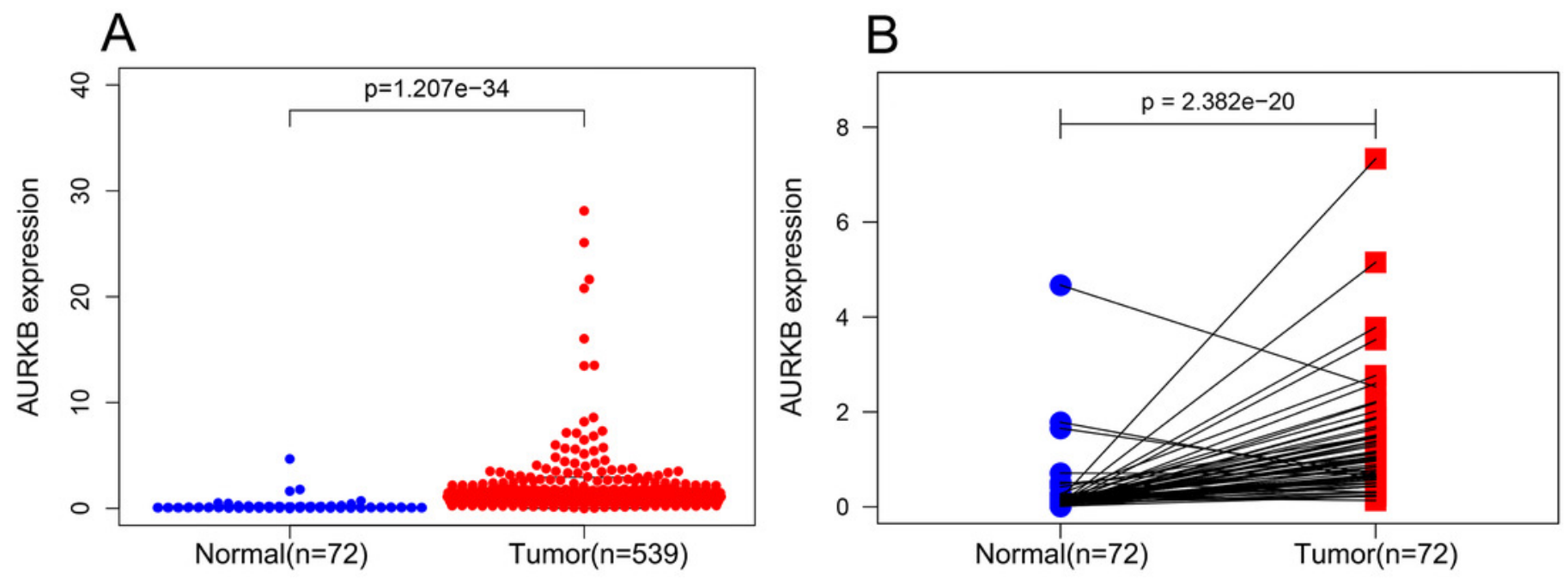
Figure 2

Association of $A U R K B$ expression with clinical parameters.

(A) age ( $p>0.05)$; (B) gender ( $p<0.05)$; (C) histological grade $(p<0.05)$; (D) pathological stage $(p<0.05)$; (E) T stage ( $p<0.05)$; (F) N stage $(p<0.05)$; (G) M stage $(p<0.05)$.
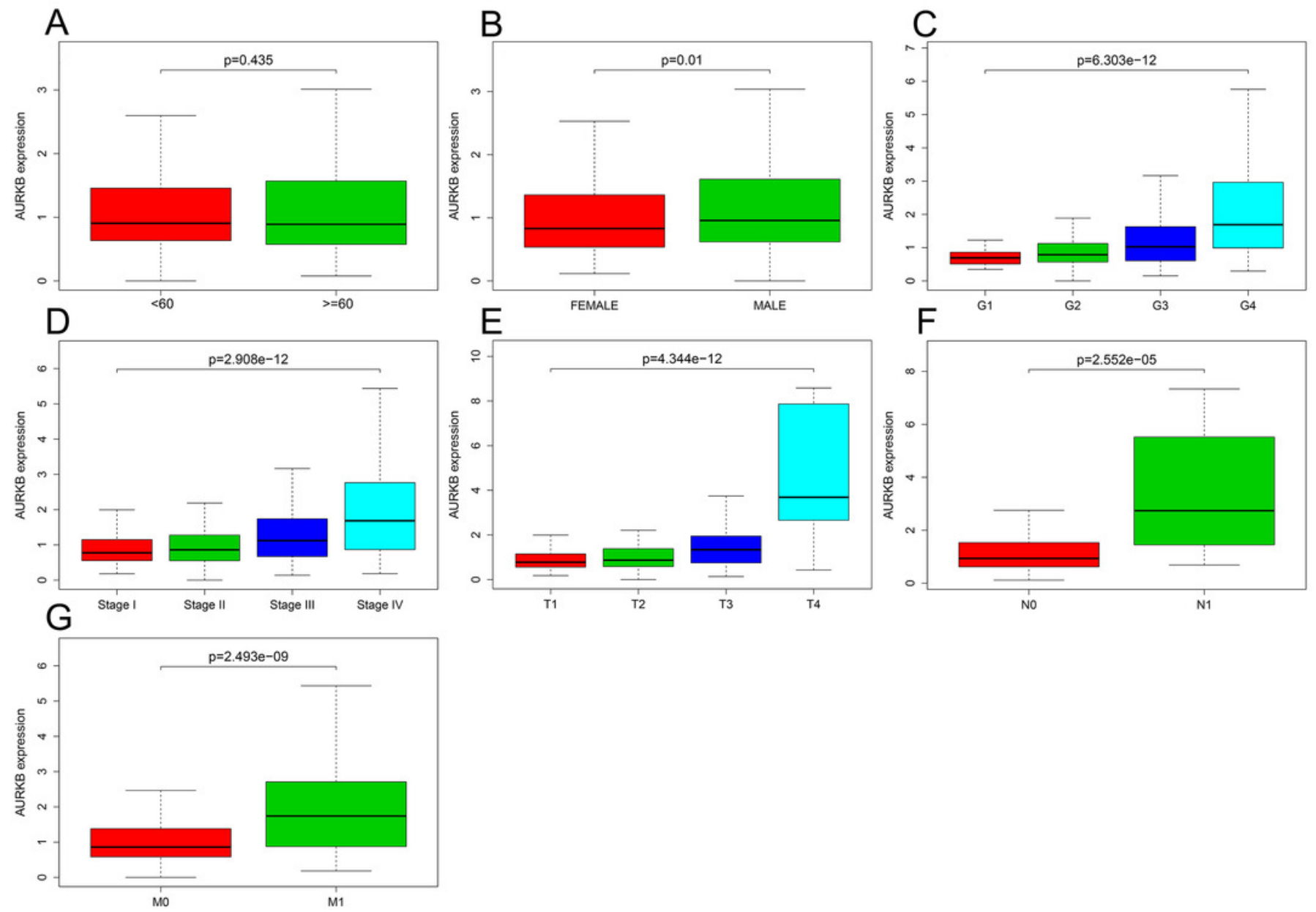
Figure 3

Kaplan-Meier survival curves of patients with $C C R C C$ based on AURKB expression levels.

(A)The Kaplan-Meier curves, (B) number at risk, and (C) number of censoring of OS in cCRCC.

(D) The Kaplan-Meier curves, (E) number at risk, and (F) number of censoring of DFS in CCRCC. High expression of AURKB was correlated with poorer OS and DFS in cCRCC patients.
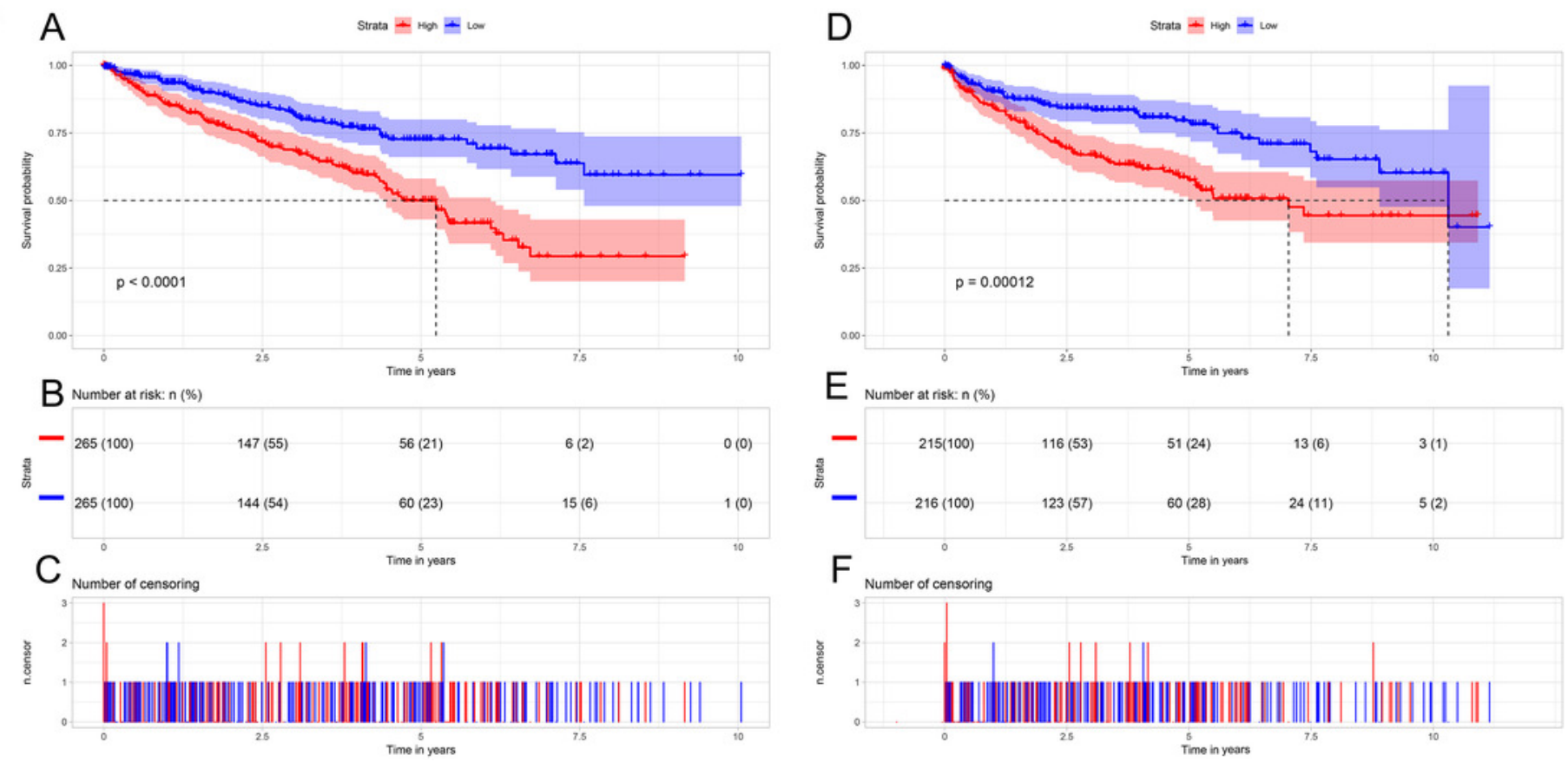

$E_{\text {Numberatisich n(s) }}$
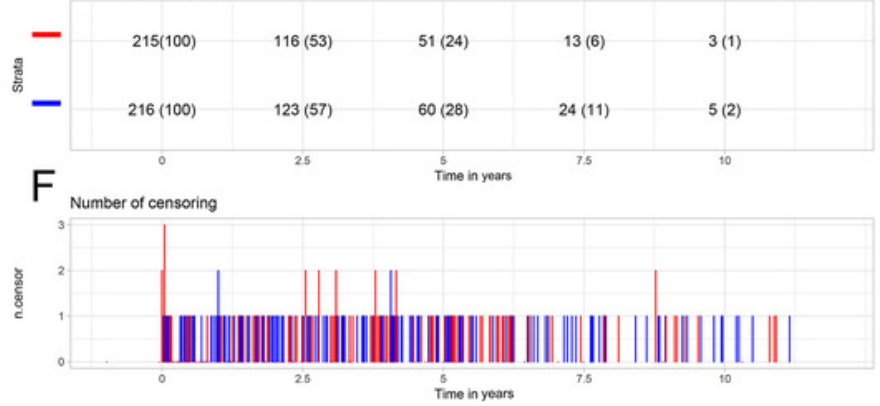
Figure 4

Forest plots for multivariate cox regression analyses.

(A) Age, histological grade, pathological stage and AURKB are independently correlated with OS; (B) Histological grade, pathological stage and AURKB are independently associated with DFS.

A

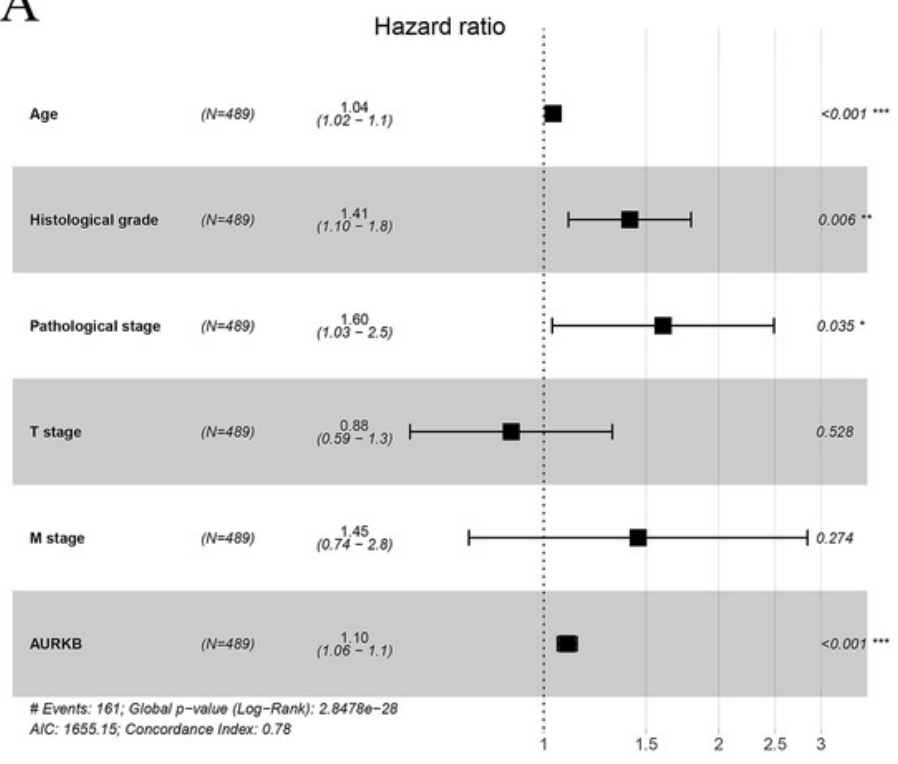

$\mathrm{B}$

Hazard ratio

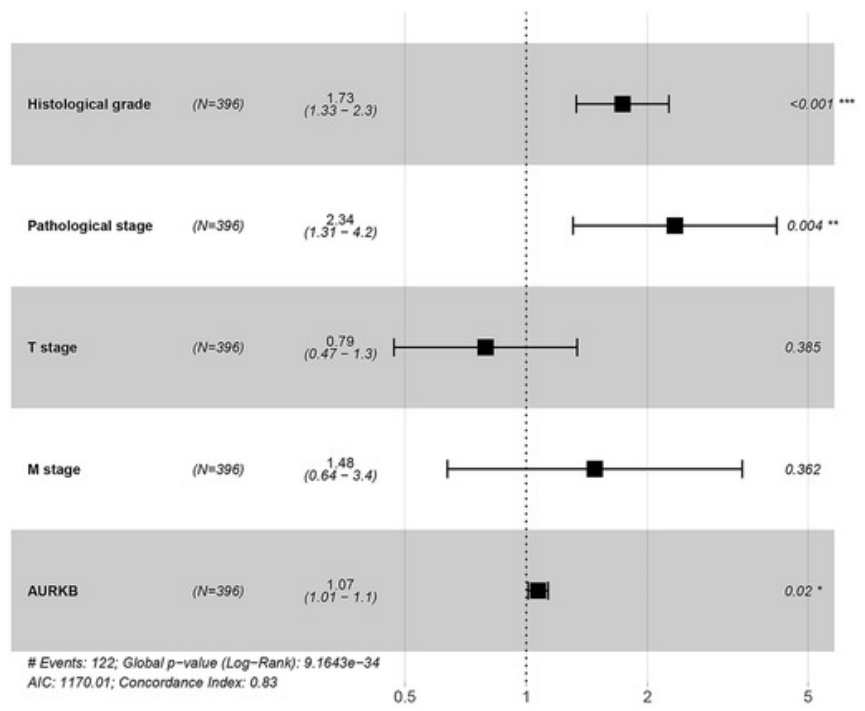


Figure 5

Nomogram and ROC plots for the prediction of outcome in patients with cCRCC.

Nomogram for the prediction of OS (A) and PFS (B) at 3 and 5 years after surgery. ROC curve evaluated the accuracy of the two models ( $C$ and $D)$, and the areas under the ROC curve were 0.792 (3-year OS), 0.748 (5-year OS), 0.851 (3-year DFS) and 0.837 (5-year DFS), and indicated a good accuracy.
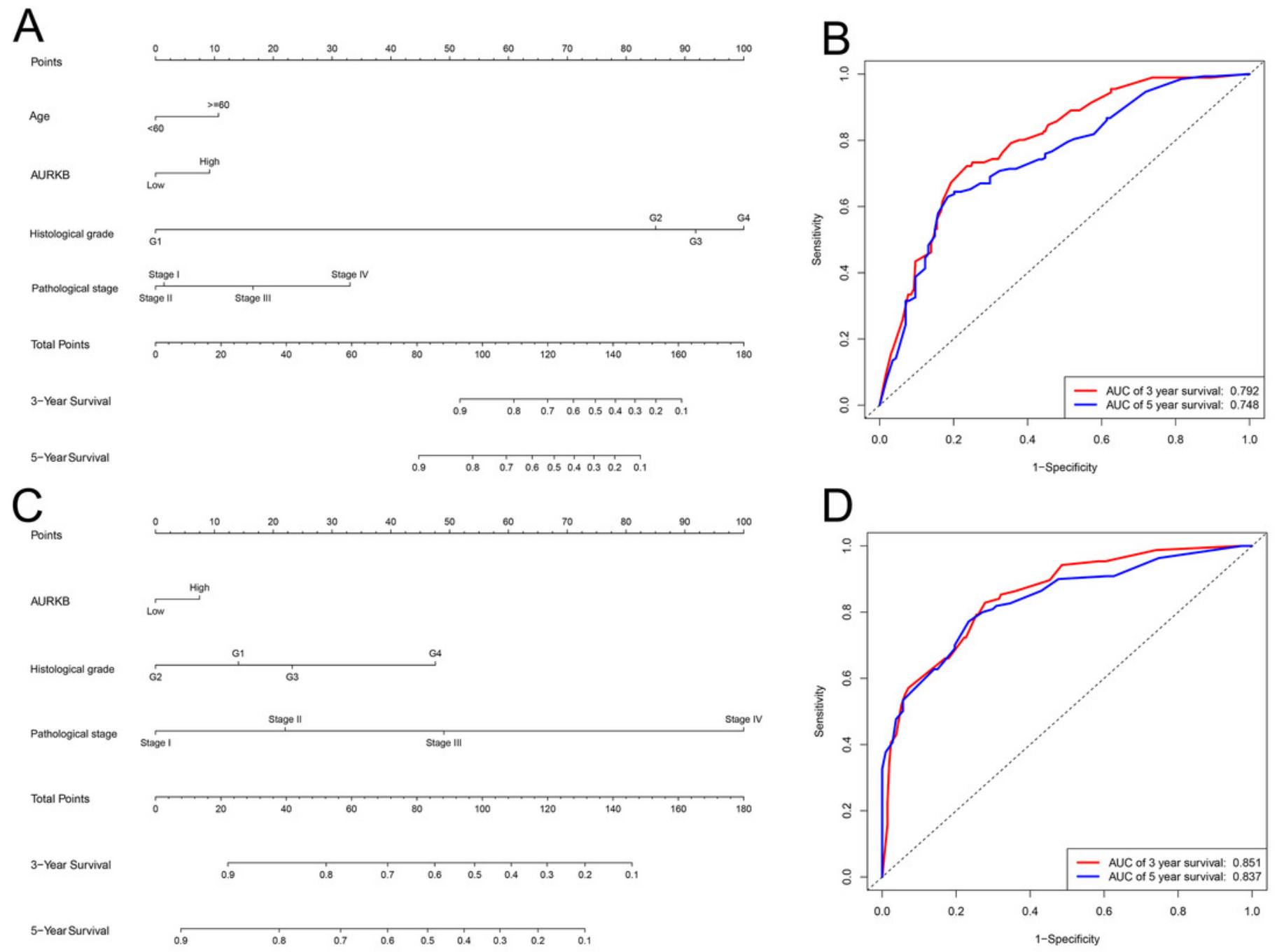
Figure 6

Drugs sensitivity analysis of $\mathrm{CCRCC}$ cell ines.

(A) Genentech Cpd 10, (B) Cabozantinib, (C) Axitinib. Those cell lines whose IC50 value greater than max screening concentration was regarded as resistant to target drugs. Blue represents sensitive $c C R C C$ cell lines to target drugs; red indicates resistant $c c R C C$ cell lines to target drugs; IC50: natural log half maximal inhibitory concentration; AUC: Area under the dose-response curve.
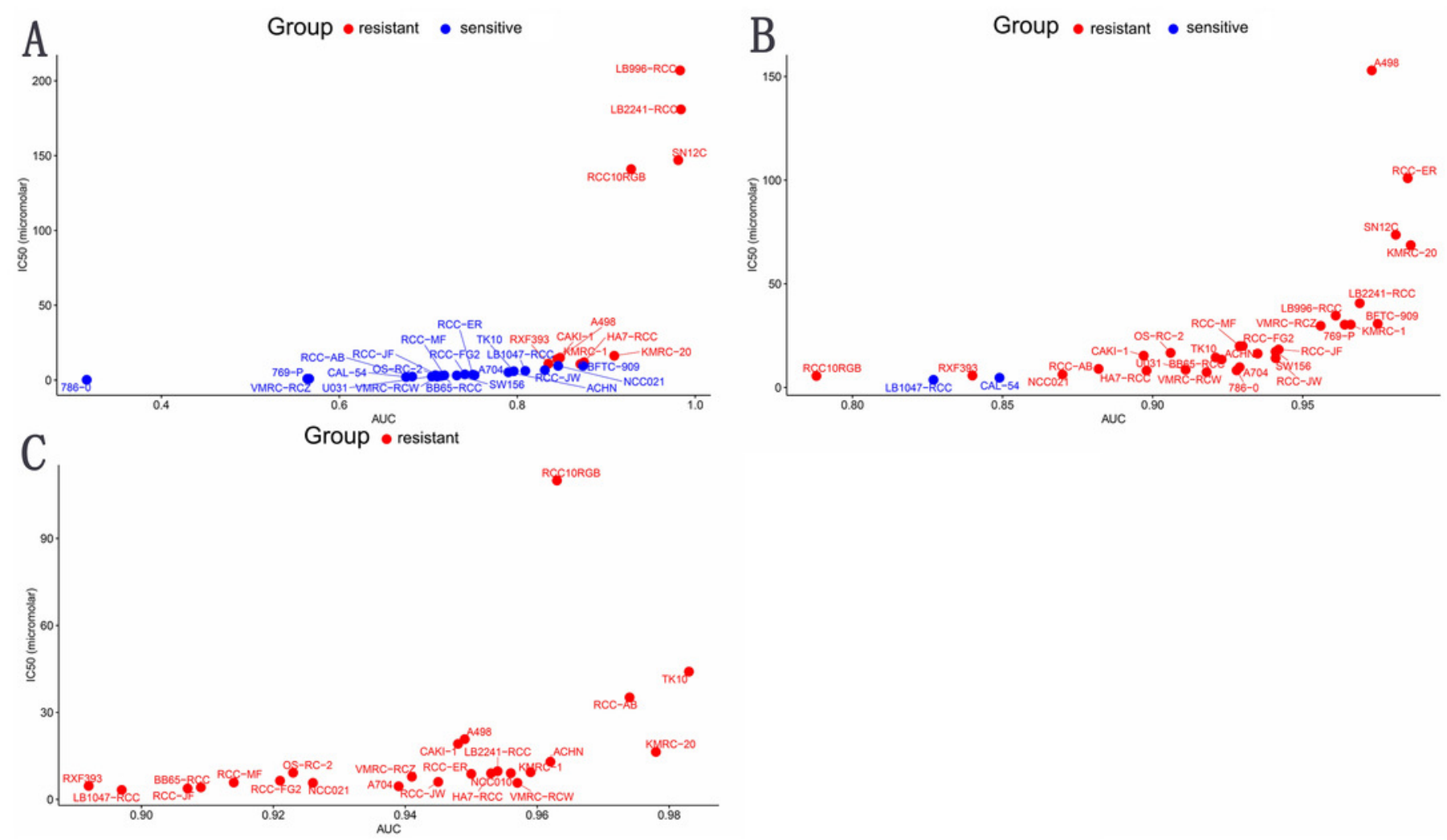
Figure 7

Enrichment plots from gene set enrichment analysis (GSEA).

(A) Enrichment sore, (B) gene sets. Intestinal immune network for IgA production, cytokinecytokine receptor interaction, natural killer cell mediated cytotoxicity, cell cycle, and cell adhesion molecules (CAMs) might be highly correlated with progression of ccRCC.

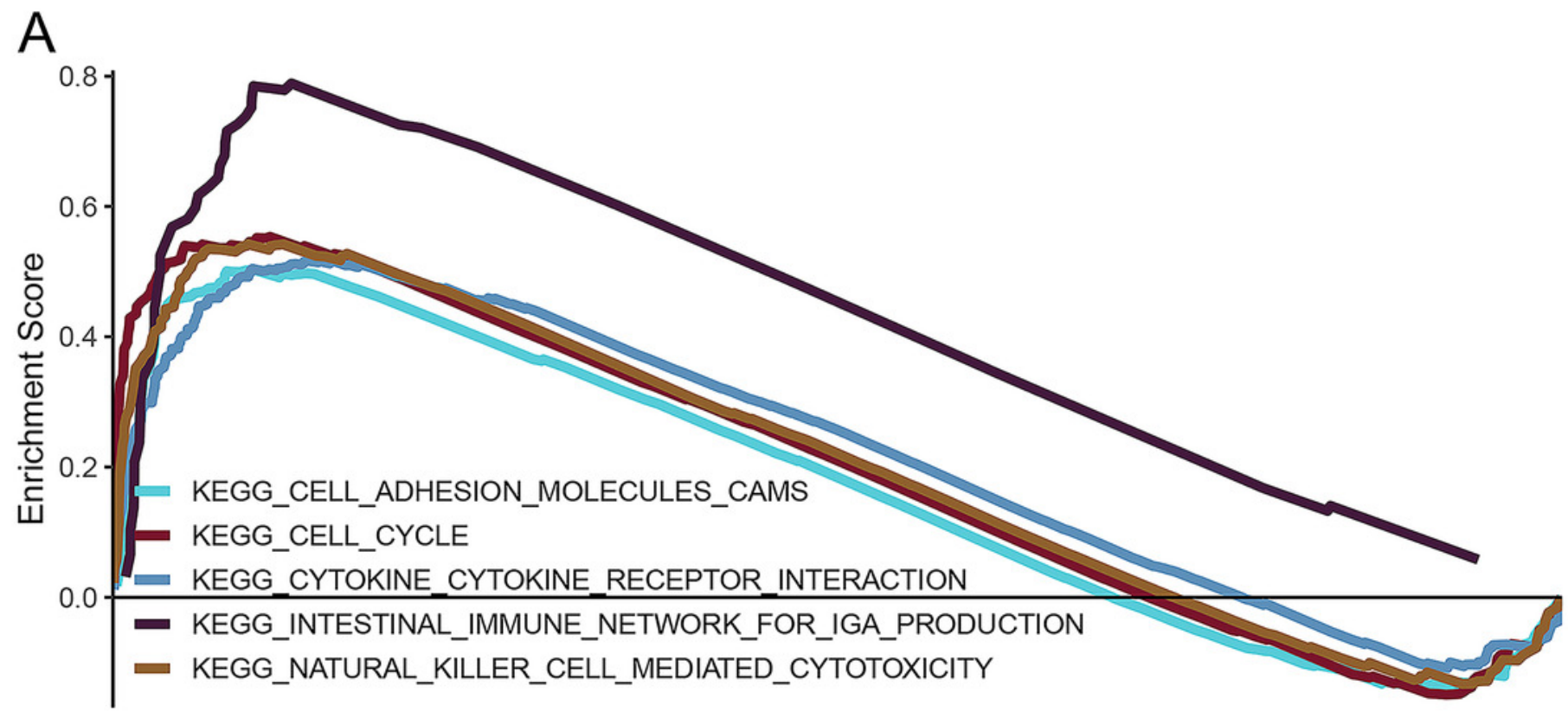

B

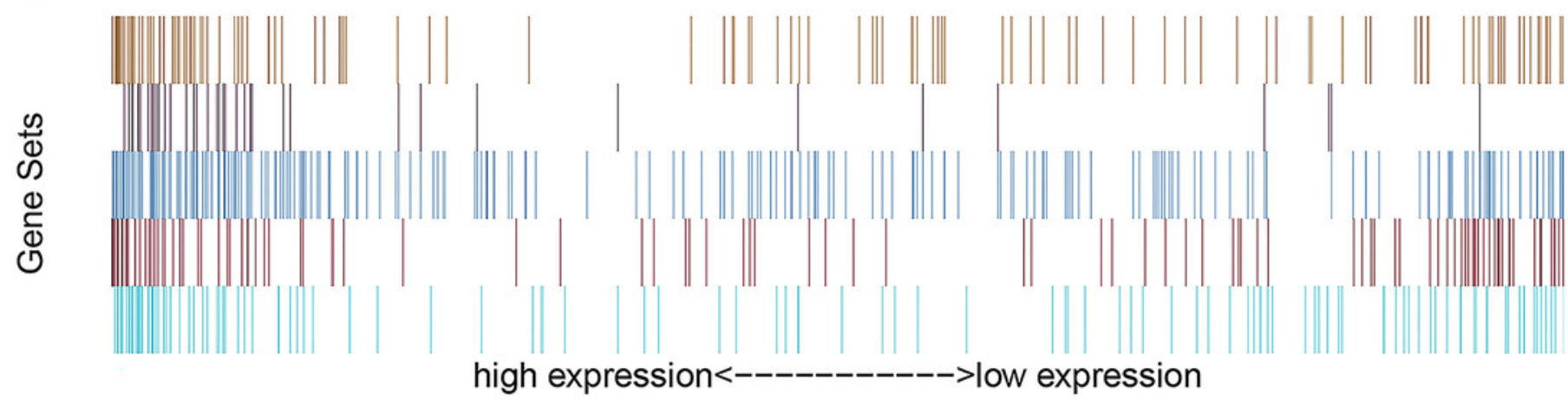


Table $\mathbf{1}$ (on next page)

Clinical data of the $c$ RCC patients. 


\begin{tabular}{|c|c|c|c|}
\hline Clinical parameters & Variable & Total (530) & Percentages $(\%)$ \\
\hline \multirow[t]{2}{*}{ Age } & $<60$ & 245 & $46 \%$ \\
\hline & $\geq 60$ & 285 & $54 \%$ \\
\hline \multirow[t]{2}{*}{ Gender } & Female & 186 & $35.56 \%$ \\
\hline & Male & 344 & $64.44 \%$ \\
\hline \multirow[t]{6}{*}{ Histological grade } & G1 & 14 & $2.64 \%$ \\
\hline & $\mathrm{G} 2$ & 227 & $42.83 \%$ \\
\hline & G3 & 206 & $38.86 \%$ \\
\hline & G4 & 75 & $14.15 \%$ \\
\hline & GX & 5 & $0.94 \%$ \\
\hline & Unknow & 3 & $0.56 \%$ \\
\hline \multirow[t]{5}{*}{ Pathological stage } & Stage I & 265 & $50.00 \%$ \\
\hline & Stage II & 57 & $10.75 \%$ \\
\hline & Stage III & 123 & $23.20 \%$ \\
\hline & Stage IV & 82 & $15.47 \%$ \\
\hline & Unknow & 3 & $0.56 \%$ \\
\hline \multirow[t]{4}{*}{ T stage } & $\mathrm{T} 1$ & 271 & $51.21 \%$ \\
\hline & $\mathrm{T} 2$ & 69 & $12.84 \%$ \\
\hline & $\mathrm{T} 3$ & 179 & $33.89 \%$ \\
\hline & $\mathrm{T} 4$ & 11 & $2.04 \%$ \\
\hline \multirow[t]{2}{*}{ M stage } & M0 & 420 & $79.24 \%$ \\
\hline & M1 & 78 & $14.71 \%$ \\
\hline
\end{tabular}




\begin{tabular}{cccc}
\hline & Mx & 30 & $5.66 \%$ \\
N stage & Unknow & 2 & $0.37 \%$ \\
N0 & 239 & $45.09 \%$ \\
N1 & 16 & $3.01 \%$ \\
Disease free Status & Recurred/Progresse & 125 & $51.88 \%$ \\
& d & 275 & $23.58 \%$ \\
& Disease free & 308 & $58.11 \%$ \\
& Unknow & 97 & $18.30 \%$ \\
& Death & 166 & $31.32 \%$ \\
& Alive & 364 & $68.68 \%$ \\
\hline
\end{tabular}

1 
Table 2 (on next page)

AURKB expression correlated with clinical parameters (logistic regression). 


\begin{tabular}{|c|c|c|c|}
\hline Clinical parameters & Total $(\mathrm{N})$ & $\begin{array}{c}\text { Odds ratio in } A U R K B \\
\text { expression }\end{array}$ & $p$-Value \\
\hline \multicolumn{4}{|l|}{ Age } \\
\hline$<60$ vs. $\geq 60$ & 530 & $0.92(0.65-1.30)$ & 0.6631356 \\
\hline \multicolumn{4}{|l|}{ Gender } \\
\hline Female vs. Male & 530 & $1.49(1.04-2.13)$ & 0.02927836 \\
\hline \multicolumn{4}{|l|}{ Histological grade } \\
\hline G1/G2 vs. G3/G4 & 523 & $2.44(1.72-3.48)$ & $6.97 \mathrm{E}-07$ \\
\hline \multicolumn{4}{|l|}{ Pathological stage } \\
\hline Stage I vs. Stage II & 326 & $1.17(0.65-2.08)$ & 0.5907123 \\
\hline Stage I vs. Stage III & 394 & $2.26(1.46-3.52)$ & $\begin{array}{c}0.00024258 \\
5\end{array}$ \\
\hline Stage I vs. Stage IV & 352 & $3.62(2.14-6.28)$ & $2.42683 \mathrm{E}-06$ \\
\hline \multicolumn{4}{|l|}{ T stage } \\
\hline T1/T2 vs. T3/T4 & 530 & $2.84(1.97-4.14)$ & $3.12 \mathrm{E}-08$ \\
\hline \multicolumn{4}{|l|}{ Lymph nodes (N stage) } \\
\hline N0 vs. N1 & 255 & $4.75(1.48-21.10)$ & 0.01705434 \\
\hline \multicolumn{4}{|l|}{$\begin{array}{c}\text { Distant metastasis (M } \\
\text { stage })\end{array}$} \\
\hline M0 vs. M1 & 498 & $2.99(1.78-5.17)$ & $4.8776 \mathrm{E}-05$ \\
\hline
\end{tabular}




\section{Table 3 (on next page)}

Univariate and multivariate cox regression analyses for OS and DFS in CCRCC patients. 


\begin{tabular}{|c|c|c|c|c|}
\hline \multirow[t]{2}{*}{ Variables } & \multicolumn{2}{|c|}{ Univariate analysis } & \multicolumn{2}{|c|}{ Multivariate analysis } \\
\hline & HR $(95 \% \mathrm{CI})$ & $p$-Value & HR $(95 \% \mathrm{CI})$ & $p$-Value \\
\hline \multicolumn{5}{|l|}{ Overall survival } \\
\hline Age & $1.03(1.01-1.04)$ & $\begin{array}{c}0.0000022 \\
9\end{array}$ & $1.03(1.02-1.05)$ & $\begin{array}{c}0.0000010 \\
7\end{array}$ \\
\hline Gender & $0.93(0.67-1.28)$ & $\begin{array}{c}0.6629365 \\
83\end{array}$ & & \\
\hline Histological grade & $2.29(1.85-2.83)$ & $1.94 \mathrm{E}-14$ & $1.40(1.10-1.79)$ & $\begin{array}{c}0.0059374 \\
57\end{array}$ \\
\hline Pathological stage & $1.88(1.64-2.16)$ & 4.67E-20 & $1.60(1.03-2.48)$ & $\begin{array}{c}0.0348976 \\
61\end{array}$ \\
\hline T stage & $1.94(1.63-2.29)$ & $1.5 \mathrm{E}-14$ & $0.87(0.58-1.31)$ & $\begin{array}{c}0.5280852 \\
68\end{array}$ \\
\hline M stage & $4.28(3.10-5.90)$ & $7.45 \mathrm{E}-19$ & $1.45(0.74-2.84)$ & $\begin{array}{c}0.2740334 \\
2\end{array}$ \\
\hline$A U R K B$ & $1.13(1.09-1.16)$ & $2.42 \mathrm{E}-13$ & $1.09(1.05-1.14)$ & $\begin{array}{c}0.0000027 \\
6\end{array}$ \\
\hline \multicolumn{5}{|l|}{$\begin{array}{c}\text { Disease free } \\
\text { survival }\end{array}$} \\
\hline Age & $1.00(0.99-1.02)$ & $\begin{array}{c}0.2094769 \\
6\end{array}$ & & \\
\hline Gender & $1.35(0.91-2.01)$ & $\begin{array}{c}0.1322015 \\
37\end{array}$ & & \\
\hline Histological grade & $2.97(2.29-3.83)$ & $\begin{array}{c}8.11792 \mathrm{E}- \\
17\end{array}$ & $1.73(1.33-2.25)$ & $\begin{array}{c}4.49123 \mathrm{E}- \\
05\end{array}$ \\
\hline Pathological stage & $2.65(2.22-3.17)$ & $\begin{array}{c}5.19396 \mathrm{E}- \\
27\end{array}$ & $2.33(1.30-4.18)$ & $\begin{array}{c}0.0042232 \\
84\end{array}$ \\
\hline
\end{tabular}




\begin{tabular}{ccccc}
\hline T stage & $2.5(2.02-3.08)$ & $1.92212 \mathrm{E}-$ & $0.79(0.46-1.33)$ & 0.3849238 \\
& & 17 & & 05 \\
& & & & \\
& & $1.95879 \mathrm{E}-$ & $1.47(0.63-3.43)$ & 0.3617811 \\
M stage & $8.52(5.87-12.37)$ & 29 & & 14 \\
& & & & 0.0199733 \\
& & & & 52 \\
\hline
\end{tabular}

1 
Table 4 (on next page)

Drugs sensitivity analysis of ccRCC cell lines. 


\begin{tabular}{|c|c|c|c|c|c|c|c|c|c|c|c|}
\hline \multicolumn{6}{|c|}{ Genentech Cpd 10 vs. Cabozantinib } & \multicolumn{6}{|c|}{ Genentech Cpd 10 vs. Axitinib } \\
\hline $\begin{array}{c}\text { Dru } \\
\text { g }\end{array}$ & $\begin{array}{l}\text { Tota } \\
1(\mathrm{~N})\end{array}$ & $\begin{array}{l}\text { Sens } \\
\text { itive }\end{array}$ & $\begin{array}{l}\text { Resi } \\
\text { stent }\end{array}$ & $\chi^{2}$ & $\begin{array}{c}p- \\
\text { Valu } \\
\mathrm{e}\end{array}$ & Drug & $\begin{array}{l}\text { Tota } \\
1(\mathrm{~N})\end{array}$ & $\begin{array}{l}\text { Sens } \\
\text { itive }\end{array}$ & $\begin{array}{l}\text { Resi } \\
\text { stent }\end{array}$ & $\chi^{2}$ & $\begin{array}{c}p- \\
\text { Valu } \\
\text { e }\end{array}$ \\
\hline $\begin{array}{l}\text { Gen } \\
\text { ente } \\
\text { ch }\end{array}$ & 31 & 21 & 10 & $\begin{array}{l}22.3 \\
95\end{array}$ & $\begin{array}{l}2.22 \\
\text { E-06 }\end{array}$ & $\begin{array}{l}\text { Gen } \\
\text { ente } \\
\text { ch }\end{array}$ & 31 & 21 & 10 & $\begin{array}{l}23.5 \\
08\end{array}$ & $\begin{array}{l}1.24 \\
4 \mathrm{E}- \\
06\end{array}$ \\
\hline $\begin{array}{c}\text { Cpd } \\
10\end{array}$ & & & & & & $\begin{array}{c}\text { Cpd } \\
10\end{array}$ & & & & & \\
\hline $\begin{array}{l}\mathrm{Cab} \\
\text { ozan } \\
\text { tinib }\end{array}$ & 31 & 2 & 29 & & & $\begin{array}{l}\text { Axiti } \\
\text { nib }\end{array}$ & 24 & 0 & 24 & & \\
\hline
\end{tabular}




\section{Table 5 (on next page)}

Gene sets enriched in the high AURKB expression phenotype. 


\begin{tabular}{|c|c|c|c|}
\hline Gene set name & NES & $\begin{array}{l}\text { NOM } p- \\
\text { value }\end{array}$ & $\begin{array}{l}\text { FDR q- } \\
\text { value }\end{array}$ \\
\hline KEGG_AUTOIMMUNE_THYROID_DISEASE & 816 & & $0^{0.003317}$ \\
\hline KEGG_INTESTINAL_IMMUNE_NETWORK_FOR_I & \multicolumn{2}{|l|}{2.3240} & 0.004554 \\
\hline GA_PRODUCTION & \multicolumn{2}{|l|}{876} & 952 \\
\hline KEGG_ANTIGEN_PROCESSING_AND_PRESENTAT & \multicolumn{3}{|c|}{2.20650 .0078890 .012016} \\
\hline ION & 759 & 546 & 102 \\
\hline KEGG_CYTOKINE_CYTOKINE_RECEPTOR_INTER & \multicolumn{3}{|c|}{2.16960 .0019150 .013810} \\
\hline ACTION & 072 & 709 & 257 \\
\hline KEGG_ASTHMA & 2.1645 & & $0^{0.011436}$ \\
\hline KEGG_TYPE_I_DIABETES_MELLITUS & 2.1399 & \multicolumn{2}{|c|}{393} \\
\hline KEGG_PRIMARY_IMMUNODEFICIENCY & $\begin{array}{r}2.0994 \\
904\end{array}$ & & 0.014886 \\
\hline KEGG_GRAFT_VERSUS_HOST_DISEASE & 2.0993 & & 0.013095 \\
\hline KEGG_ALLOGRAFT_REJECTION & 2.0911 & & 181 \\
\hline \multirow{2}{*}{ KEGG_BASE_EXCISION_REPAIR } & \multicolumn{3}{|c|}{2.04780 .0019010 .016551} \\
\hline & 24 & 141 & 593 \\
\hline \multirow{2}{*}{ KEGG_HOMOLOGOUS_RECOMBINATION } & \multicolumn{3}{|c|}{2.04730 .0039130 .015096} \\
\hline & 04 & 894 & 117 \\
\hline KEGG_NATURAL_KILLER_CELL_MEDIATED_CY & 2.0085 & 0.015655 & 0.019628 \\
\hline TOTOXICITY & 354 & 577 & 806 \\
\hline KEGG_CYTOSOLIC_DNA_SENSING_PATHWAY & 2.0077 & & 0.018204 \\
\hline
\end{tabular}




\begin{tabular}{|c|c|c|c|}
\hline & 2 & & 125 \\
\hline \multirow{2}{*}{ KEGG_VIRAL_MYOCARDITIS } & \multicolumn{3}{|c|}{1.99340 .0099400 .019238} \\
\hline & 07 & 358 & 696 \\
\hline \multirow{2}{*}{ KEGG_HEMATOPOIETIC_CELL_LINEAGE } & \multicolumn{3}{|c|}{1.95260 .0058250 .024869} \\
\hline & 478 & 243 & 524 \\
\hline \multirow{2}{*}{ KEGG_DNA_REPLICATION } & \multicolumn{3}{|c|}{1.94700 .0134610 .024576} \\
\hline & 055 & 539 & 483 \\
\hline \multirow{2}{*}{ KEGG_SYSTEMIC_LUPUS_ERYTHEMATOSUS } & \multicolumn{3}{|c|}{1.94170 .0139440 .023910} \\
\hline & 096 & 224 & 57 \\
\hline \multirow{2}{*}{ KEGG_LEISHMANIA_INFECTION } & \multicolumn{3}{|c|}{1.92090 .0275590 .026700} \\
\hline & 716 & 055 & 974 \\
\hline \multirow{2}{*}{ KEGG_CELL_CYCLE } & \multicolumn{3}{|c|}{1.89690 .0255900 .030597} \\
\hline & 755 & 552 & 683 \\
\hline \multirow{2}{*}{ KEGG_CELL_ADHESION_MOLECULES_CAMS } & \multicolumn{3}{|c|}{1.85930 .0320640 .037772} \\
\hline & 365 & 13 & 134 \\
\hline \multirow{2}{*}{ KEGG_PROTEASOME } & \multicolumn{3}{|c|}{1.82960 .0282480 .044589} \\
\hline & 527 & 588 & 847 \\
\hline
\end{tabular}

1 NES: normalized enrichment score; NOM: nominal; FDR: false discovery rate. Gene sets with 2 NOM $p$-value $<0.05$ and FDR q-value $<0.05$ were regarded as significantly enriched. 